TECHNICAL NOTES AND MANUALS

\title{
A Basic Model of
} Performance-Based Budgeting

Marc Robinson and Duncan Last

Fiscal Affairs Department

I NTER NATIONAL MONETARY FUND 


\section{INTERNATIONAL MONETARY FUND}

Fiscal Affairs Department

\section{A Basic Model of Performance-Based Budgeting \\ Prepared by Marc Robinson and Duncan Last \\ Authorized for distribution by Carlo Cottarelli}

September 2009

DISCLAIMER: The views expressed in this technical note are those of the authors and should not be attributed to the IMF, its Executive Board, or its management.

\begin{tabular}{|l|l|}
\hline JEL Classification Numbers: & D61, D73, H61, H83 \\
\hline Keywords: & $\begin{array}{l}\text { performance budgeting, expenditure prioritization, managing-for-results, } \\
\text { program budgeting, expenditure review, program classification }\end{array}$ \\
\hline Author's E-mail Address: & marc@pfmresults.com; dlast@imf.org \\
\hline
\end{tabular}




\title{
TECHNICAL NOTES AND MANUALS
}

\section{A Basic Model of Performance-Based Budgeting}

\author{
Marc Robinson and Duncan Last
}

This technical note addresses the following main questions:

- What are the characteristics of a basic model of performance-based budgeting?

- How should low-income countries approach performance-based budgeting?

- What preconditions should exist before starting?

- What forms of performance-based budgeting should low income countries avoid?

\section{Objectives of the Note*}

The primary objective of this technical note is to elaborate a basic model of performancebased budgeting that could be considered for the following two categories of countries:

- those that wish to introduce a performance-based budgeting system while minimizing the complexities and costs of doing so; and

- those with limited resources and capacity, including appropriate low-income countries (LICs).

The note emphasizes necessary preconditions for any move to performance-based budgetingrecognizing that performance-based budgeting, even in its basic form, should not be considered in countries with seriously dysfunctional public financial management (PFM) and governance systems.

More complex performance-based budgeting models exist. This note describes these, and outlines reasons why these models of performance-based budgeting may not be appropriate in many countries.

\footnotetext{
* An earlier version of this note was previously issued as part of a series of technical notes on the IMF's Public Financial Management Blog (http://blog-pfm.imf.org).

Marc Robinson was a Senior Economist in the Fiscal Affairs Department of the International Monetary Fund; Duncan Last is a Senior Economist in the Fiscal Affairs Department.

The sequencing or implementation planning for introducing a performance-based budgeting approach is not discussed here.
} 


\section{What Is Performance-Based Budgeting?}

Performance-based budgeting aims to improve the efficiency and effectiveness of public expenditure by linking the funding of public sector organizations to the results they deliver, making systematic use of performance information. There are a number of models of performance-based budgeting that use different mechanisms to link funding to results. Some have very sophisticated features and require the support of correspondingly sophisticated public management systems (see below), while others focus more on the basics.

Performance-based budgeting should not be seen as an isolated initiative. It should be viewed, rather, as part of a set of broader reforms—often referred to as managing-for-resultsdesigned to focus public management more on results delivered and less on internal processes. These broader reforms include civil service reforms designed to increase the motivation and incentives of public employees; organizational restructuring to increase the focus on service delivery and improve coordination (e.g., creation of agencies and reduction of the number of ministries); and institutional and oversight changes to strengthen public accountability for performance. Action on these and a range of related fronts is necessary if the efficiency and effectiveness of public expenditure is to be substantially improved.

\section{The Model}

The most basic form of performance-based budgeting is that which aims to ensure that, when formulating the government budget, key decision makers systematically take into account the results to be achieved by expenditure. This is what is sometimes referred to as "performance-informed budgeting."

The essential requirements for this most basic form of performance-based budgeting are

- information about the objectives and results of government expenditure, in the form of key performance indicators and a simple form of program evaluation; and

- a budget preparation process designed to facilitate the use of this information in budget funding decisions, including simple expenditure review processes and spending ministry budget decisions.

A program classification of expenditure in the budget is also highly recommended. By classifying expenditure into groups of similar services with similar objectives, a program budget helps budget decision makers compare the costs and benefits of expenditure options.

Systematic consideration of results in the budget preparation process has the potential to

- improve expenditure prioritization (the capacity to allocate limited resources to where they will do the most good); and 
- encourage line ministries to spend more efficiently and effectively by making them aware that their performance will influence their level of funding and by reducing or streamlining the controls that impede good performance.

If, for example, certain government programs are not delivering their intended outcomes or are doing so at an unreasonably high cost, focusing the attention of budget decision makers on this fact during the budget preparation process can encourage them to consider whether the program should be abolished, scaled-down, or fundamentally restructured.

Basic performance-based budgeting can also improve aggregate fiscal discipline. Improving expenditure prioritization means an improved capacity to make "fiscal space" for new spending initiatives without commensurately increasing aggregate expenditure. It also facilitates fiscal consolidation when this is necessary by helping government target spending cuts at its least effective or least socially important programs. And insofar as performance-based budgeting (and managing-for-results generally) succeeds in improving the efficiency of government services, it enables government to do "more with less" and helps contain the long-term upward pressure on aggregate public expenditure.

\section{Performance-based budgeting fits naturally with a medium-term budget framework,} although the latter should not be thought of as a prerequisite for the former. Like performancebased budgeting, a medium-term budget framework aims to improve expenditure prioritization (although performance-based budgeting is much more focused on managing the efficiency and effectiveness of public expenditure). The best way to improve expenditure policy formulation is both to make maximum use of performance information and to consider the medium-term cost implications of expenditure choices.

\section{Information on Objectives and Results}

Systematic information about the efficiency and effectiveness of public expenditure is the most fundamental tool of performance-based budgeting, and of managing-for-results more generally. Only if reliable and timely information is available about the results being delivered by government actions will it be possible to make performance-informed budget decisions.

Basic performance-based budgeting can, therefore, only be successful if every spending agency is required to

- explicitly define the outcomes that its services (outputs) aim to deliver to the community; and

- provide to the ministry of finance and key political decision makers during the budget preparation process key performance indicators to measure the effectiveness and efficiency of its services. 
The biggest challenge in the development of a basic model of performance-based budgeting is keeping this performance information simple, affordable, and usable. All too often, newcomers to performance-based budgeting, including LICs, have set out to develop sophisticated performance information systems over short time periods (as little as a year or two). They fail to fully realize that such information is expensive and requires skilled human resources which may not be readily available or affordable. It is worth remembering here that similar systems in OECD countries took decades to develop.

Realism and the recognition of financial and human resource constraints suggest that countries should aim initially to develop only a handful of key performance indicators for each ministry and subsequently for each program.

Evaluation is important even in a basic model because indicators alone are often insufficient to judge program performance. However, it is important to avoid the allocation of excessive resources to a "monitoring and evaluation" industry employing complex evaluation methodologies. In a basic model of performance-based budgeting, the focus could (at least initially) be primarily upon socalled "desk" evaluations. ${ }^{1}$

\section{Budget Processes to Use Performance Information}

The availability of the right performance information is a necessary-but not a sufficientcondition for the success of performance-based budgeting. The performance information also has to be actually used in the budget process. There have been a number of examples of countries that have made great efforts to develop the necessary performance information-and have also placed the budget on a program basis—but have then failed to make any significant use of this information when deciding the budget.

Experience shows that, in order for performance-based budgeting to work, reconsideration of spending priorities and program performance need to be formally integrated into the budget process. These routines need to be designed so as to make maximum use of available information on program performance. The precise form such routines should take should be country-specific, depending in part on national specifics such as the characteristics of the political and administrative systems. However, some key common elements are

- a "strategic phase" early on in the budget cycle, which incorporates a preliminary consideration of the government's broad expenditure priorities;

\footnotetext{
${ }^{1}$ The primary elements of which are an analysis of (i) the importance of the program objective (is the program attempting to deliver something that is really important to the society and in line with the government's stated policy priorities?); (ii) what available performance information indicates about the effectiveness and efficiency with which these objectives are being achieved; and (iii) the program logic — whether the strategy by which the program attempts to achieve its intended outcome makes sense, and whether there is sufficient coordination among different actors (especially in the context of decentralization), given the experience of other countries and relevant theory.
} 
- an expenditure review process — even if a very simple one-that is designed to keep under review the appropriateness and effectiveness of existing programs and that can use performance information to help identify those that can be cut back, or even eliminated, as well as those that might be expanded;

- a systematic process for scrutinizing all proposed new spending initiatives; and

- a requirement that all spending ministry budget submissions be supported by information on the effectiveness and efficiency of its expenditure.

Expenditure review processes deserve special emphasis. Without systematic spending review, it becomes much harder to make fiscal space for new priorities. And it is in the assessment of existing expenditure programs that performance information is most useful.

\section{Performance-based budgeting does not necessarily require elaborate and formal national} planning processes. Medium-term sectoral planning, particularly in the service delivery sectors, such as health, education, infrastructure, and economic activities, can provide essential performance information for line ministries. However, to ensure effective synergy between sectoral plans and performance budgets, the planning process will need to be fully integrated into the budget cycle. National-level planning processes can also provide a useful means to coordinate and prioritize sectoral plans around key national priorities, such as economic growth and poverty reduction, but these should remain light and adaptable, and fully integrated with the "strategic phase" of the budget cycle mentioned above.

Where the planning process is institutionally separated from the budget process, the introduction of a performance-based budgeting approach may not deliver the desired results. In some countries, planning commissions/ministries formulate bulky five- or ten-year plans that are intended to guide public expenditure. Many of these countries experience chronic difficulty in ensuring that the priorities identified in the planning process are reflected in the allocation of resources in the annual budget. Some in these countries view performance-based budgeting as the solution to this problem, in the belief that improving planning through the use of better performance information will lead to greater respect for the plan in budget formulation. Where budget decision makers do not take the priorities identified in the plan seriously, however, this may lead to possible conflict between planning and budgeting objectives, and result in weakening government policy prioritization.

\section{A Program Budget}

\section{A program budget classifies expenditure by types of service and objectives, rather than-as} in traditional budgeting - by types of inputs (salaries, supplies, equipment, etc.). This is a powerful tool for performance-based budgeting because it indicates how much money is being directed at achieving particular outcomes for the community. This enables budget decision makers to assess the benefits and efficiency of programs relative to their costs. 
Program budgeting is, therefore, an element of performance-based budgeting that is highly recommended for those countries that have the resources and capacity to introduce it. However, for those countries not yet ready to move to a program budget, the two elements outlined above-better performance information and budget processes to use that informationcan still deliver significant benefits.

A program budget requires the development and public presentation of key performance and cost information about each program, including

- the program's objectives and how these link to national and sectoral priorities;

- the key services "outputs" that the program delivers;

- how the program is intended to achieve its stated objectives (e.g., activities, projects, etc.);

- key performance indicators and evaluation results by program; and

- program costs.

Under program budgeting, the budget preparation process should be program based. That is, agencies should present and justify their budgets in terms of programs with supporting cost and performance information. In addition, the program performance information should be presented to the legislature and public as part of the budget documentation.

Program budgeting usually also involves legal appropriation of funds in the budget on a program basis. ${ }^{2}$

Program classification is a demanding task that requires careful design and coordination. General program classification principles are treated elsewhere ${ }^{3}$ and are, therefore, not covered in detail in this note. However, a few key points are worth noting:

- Programs should be directly linked, to the maximum degree possible, to outcomes and outputs.

- The program classification should comprehensively cover all government expenditure. In many LICs, program classifications have been introduced that have excluded large elements of expenditure—such as civil service employment costs or capital expenditure. With such major omissions, programs become questionable as a basis for making judgments about expenditure priorities.

- A program budget requires that the accounting system be enhanced to record expenditure on a continuing basis by program (as well as by the established economic and administrative classifications).

\footnotetext{
${ }^{2}$ There are, however, some countries where budget preparation takes place on a program basis but parliament appropriates agency budgets on an aggregated basis. Ultimately, this is a question of the allocation of budgetary power between the executive government and the legislature. If, as is usually the case, the principle is that the legislature should have ultimate authority over the allocation of public funds, then the budget should be appropriated by program.

${ }^{3}$ M. Robinson and H. van Eden, "Program Classification" in M. Robinson ed. (2007), Performance Budgeting: Linking Funding and Results, Palgrave Macmillan, Basingstoke (hereafter referred to as Performance Budgeting).
} 
A basic model of performance-based budgeting does not require a "perfect" program classification of expenditure. Two points are particularly relevant here:

- It makes sense to use "administration" programs within line ministries to group together the costs of support services (e.g., human resources and financial management) and overhead management-i.e., what accountants refer to as "indirect" costs. In a perfect world, best practice would be to avoid such programs because they are based on internal process rather than results delivered to the community. Ideally, these costs would be distributed as overheads to service delivery programs. However, in order to avoid the use of administration programs, one needs strong management accounting systems capable of allocating indirect costs to ministry "products" with a reasonable degree of accuracy. Such management accounting systems do not exist in many countries (especially LICs), and their development cannot—given the cost involved—be generally regarded as a high priority.

- Usable estimates of program costs do not require accrual accounting or budgeting. Accrual accounting is demanding, both in terms of skilled staff and the financial costs of operating the necessary systems and may not be appropriate in many countries. Accrual budgeting is even more demanding. It is true that accruals give more accurate information on program costs. However, the information on program costs generated by a "cash" budgeting system is, for the most part, sufficiently close to the mark to support considerable improvements in budget decision making. ${ }^{4}$

\section{Managerial Freedom}

The introduction of performance-based budgeting will ideally require greater flexibility for spending ministries and program managers, who are expected to become more accountable for results. ${ }^{5}$ In particular, performance-based budgeting requires

- Increased input flexibility: line managers should be given greater flexibility to choose the input mix that can most efficiently deliver services. This requires a reduction of the large number of distinct limits imposed upon expenditure by economic classification ("line item") in traditional budgeting. However, in the case of LICs, the reduction of input controls should not in general proceed as far as has been the case in some OECD countries. It will often, for example, be appropriate to maintain separate spending limits on expenditure items

${ }^{4}$ See M. Robinson "Cost Information" (in Performance Budgeting). Note in particular that while it is true that cash information ignores the costs associated with the utilization of the capital stock-which in an accrual system is measured by depreciation-it is also true that much of this cost is a "sunk" cost that is irrelevant to short-term decisions about the level of program funding.

${ }^{5}$ In principle, a performance-based budgeting approach could be introduced in a highly centralized environment, where all resource allocation decisions are taken centrally by the MoF or the Presidency. However, since budget implementation inevitably involves technical ministries, who may not necessarily share the centrally defined priorities, enhanced efficiency and effectiveness in the use of budget resources, the prime objective of performance-based budgeting, is unlikely to be achieved. 
particularly susceptible to corruption and abuse (entertainment, travel, consultancy, etc.). Insofar as civil service employment regimes remain rigid-in the sense that, once hired, civil servants cannot be fired-it may be appropriate not only to maintain line-item controls over employment costs, but also quantitative limits on ministry employment levels. And as in most developed countries, line-item controls over capital expenditure and transfer payments should be maintained.

- Administrative process flexibility: if expenditure prioritization is to be improved, it is crucial that governments have the capacity to reduce civil service employment in lowpriority or ineffective program areas. Yet, in many countries, governments are not able to even redeploy staff as needs arise. Greater civil service employment flexibility is, therefore, an important element to the success of performance-based budgeting and managing-for-results more generally. However, the appropriate degree and pace of civil service reform will vary from country to country depending, among other things, upon the quality of governance. Furthermore, in many LICs, such changes in the civil service will require significant retraining and capacity-building efforts.

\section{Readiness to Introduce Performance-Based Budgeting}

Performance-based budgeting is not, as noted above, an initiative that is appropriate for all countries. A decision about whether to introduce such a system in any specific country should be based on sober consideration of the governance conditions, the state of the basic public financial management (PFM) systems, and the available human and financial resources.

Technical improvements like performance-based budgeting cannot be expected to succeed in improving the efficiency and effectiveness of public expenditure in countries with very poor governance. If, for example, the political and bureaucratic leadership is highly corrupt and rent-seeking, with little interest in improving public sector performance, performance-based budgeting and other "managing-for-results initiatives" will be a waste of effort.

There are also a number of PFM prerequisites that should be met before any consideration is given to "second generation" initiatives such as performance-based budgeting, the most important of which are the following:

- The existence of sound macrofiscal policy management, so that spending ministry budgets do not suffer massive uncertainty about the funding they will receive during the budget year; and

- An ability to enforce the execution of budgets as planned. This requires respect of budgetary rules and procedures and the capacity to apply (and police) them in execution. It also requires good accounting and auditing procedures.

The existence of adequate staff capacity to address the informational requirements of performance-based budgeting is the main institutional prerequisite. The "scaled down" form 
of performance-based budgeting outlined in this note is, quite deliberately, one that requires a reduced set of performance information. However, even the development of such a reduced set of performance information is demanding, and for those LICs with serious capacity limitations, it may not make sense to embark on the introduction of even the simplest form of performancebased budgeting until such capacity constraints are overcome.

\section{IX. "Advanced" Forms of Performance Budgeting}

A number of "cutting edge" performance-budgeting mechanisms that have been adopted by some OECD countries are not part of the basic model proposed in this paper and should be treated with great caution by LICs and many other countries. These include

- Budget-linked performance targets: this approach to performance budgeting involves setting performance targets for all line ministries as part of the budget process. The most successful example of this approach is the U.K. "Public Service Agreement" system. ${ }^{6}$ This approach is difficult to apply in LICs because it requires

— a well-developed performance measurement system; and

- a solid information base on the relationship between funding levels and the results which the ministry can be expected to achieve. ${ }^{7}$

However, while comprehensive target setting would generally be inappropriate for LICs, selective target setting may be highly desirable (e.g., targets for vaccination rates or literacy levels).

- The production of summary program performance ratings for all programs for use in the budget preparation process. The most advanced example of such a system is the U.S. Program Assessment Rating Tool, under which the performance of each and every U.S. federal program was rated (as "effective," "moderately effective," "adequate," "ineffective," or "results not demonstrated") over a five-year period. While this system appears to operate very well in the U.S., this is only because the summary program performance ratings draw on a mass of established performance indicators and program evaluations. There are very few countries in the world that have, or could expect to develop in the short or medium terms, a sufficiently strong performance information system to make this approach work.

- Purchaser-provider systems: this approach treats line ministries like commercial businesses that are paid "prices" by the government for the services they deliver to the community. The problem with this approach is that

\footnotetext{
${ }^{6}$ See P. Smith, "Performance Budgeting in England: Public Service Agreements," (in Performance Budgeting).

${ }^{7}$ In the absence of this, targets will tend to be arbitrary. Setting arbitrary targets tends to be worse than setting no targets at all, because unreasonably demanding targets demotivate, while targets that are set too low become an excuse for continued poor performance.
} 
— it has been unsuccessful when applied on a government-wide basis, even in OECD countries, and has been successful only when applied selectively to the funding of specific sectors or specific institutions (e.g., hospitals); ${ }^{8}$ and

— it is extremely demanding of performance and cost information.

One performance budgeting tool that can be useful, if applied on a selective basis in certain sectors in LICs, is the use of information about the cost per unit of outputs (or, more rarely, outcomes) in budget planning or in formula funding more generally. ${ }^{9}$ However, additional capacity and expertise is required to collect and maintain unit cost data, which may not be justifiable or feasible for many LICs.

\section{Elements of a scaled-down performance-based} budgeting model

A "strategic" priority setting phase early in the budget cycle

An expenditure review process

Systematic scrutiny of new spending proposals

Information on efficiency and effectiveness to support budget submissions

Introduction of program budget structure

Increased managerial flexibility

\section{Advanced features to be treated with} great caution

Budget-linked performance targets

Production of summary program performance ratings

Purchaser-provider systems

\section{Conclusion}

It has been suggested that performance budgeting is entirely inappropriate for a wide range of countries, including all or most LICs. This note suggests that this is too simplistic a view. A "scaleddown" model of performance-based budgeting — which aims to make the budget preparation process more "performance-informed" — can be implemented in some LICs and could be of significant benefit to a country's development. However, this should only be attempted in those countries where sound macrofiscal policy has been established, PFM systems and procedures ensure that budgets are executed as planned, information systems are able to provide timely and reliable budgetary data, and enhanced capacities are available to handle the more demanding analysis that performance-based budgeting requires. Finally, countries with serious governance problems are unlikely to benefit much from performance-based budgeting.

\footnotetext{
${ }^{8}$ Purchaser-Provider Systems have been highly successful in the hospital sector in many countries in the form of the so-called "diagnostic related group" funding system. See M. Robinson, "Purchaser-Provider Systems" (in Performance Budgeting).

${ }^{9}$ See P. Smith, "Formula Funding and Performance Budgeting" (in Performance Budgeting).
} 


\section{APPENDIX I. Case Studies}

Among the useful case studies for countries to evaluate are the following four countries, which have introduced or are moving toward performance-based budgeting:

\section{Case 1: Mali}

The pressure to initiate the development of program budgeting in Mali came from the National Assembly which, in 1995, urged the government to "adopt a budgeting system and a budget presentation which would allow them not only to check and evaluate the consistency and coherence of budgetary proposals with existing national programs or plans but also to monitor progress of the government in general, and the line ministries in particular, toward the achievement of the objectives set in those programs and plans." The ministry of finance started a phased approach to introducing program budgeting starting with a few ministries in 1997 and completing all ministries a few years later. The resulting program budgets are sent to parliament but in a separate annex to the main budget. Programs are identified within each ministry and are aligned to the various missions that the ministry is given within the government. Support for this budget improvement process in Mali, other than in parliament, has come from having a champion in the person of the budget director and subsequent minister of finance, who took care to build the technical capacity within the ministry to guide the new approach. While the development of program budgeting in Mali has followed a classic route, it has yet to become the basis of the approved budget, which has so far limited its usefulness as a budgetary management tool.

\section{Case 2: Ethiopia}

The pressure to introduce a program structure to the budget in Ethiopia came from the prime minister, who wanted a mechanism to evaluate performance of ministries, particularly in the context of civil service reforms such as strategic planning and management and service delivery improvement. In Ethiopia, the civil service reforms went ahead without appropriate improvements in the budgetary process, i.e., ministries were undergoing major changes without any corresponding improvements in the way their budgets were being prepared or executed. In 2005, the ministry of finance, at the request of the prime minister, initiated work on introducing program budgeting on a pilot basis in three ministries. The number of ministries covered has been progressively expanded since then. The design of programs builds on the work already carried out on strategic plans for these ministries, with the intention of aligning resource allocation with the new directions being implemented under those plans. The main champion in the ministry of finance has been the minister, although the pressure for change has come from the prime minister. There has, so far, been only limited involvement of parliament. The development of program budgeting in Ethiopia is still in early days. 


\section{Case 3: South Africa}

While South Africa is not an LIC, the introduction of program budgeting there makes for an interesting case study. Pressure to improve the budgetary system came in the late 1990s on the back of broader democratic reforms. It has been fully combined with the introduction of an MTEF, and has been accompanied by moves on the audit side to performance audit. The presentation of the budget has now been fully converted to a presentation by programs, with descriptions, objectives, and expected outputs and indicators, along with the financial estimates. This budgetary approach has been implemented at the central and regional government levels and is considered one of the better implementations of program budgeting.

\section{Case 4: Slovenia}

This case study, while also not of an LIC, illustrates the pros and cons of gradual versus the "Big Bang"' approach to introducing program budgeting. An issue that often arises with such a initiative is how to handle the interim period between the pilot phase and the full introduction in all ministries, particularly how to reflect the new approach in budget documents. Slovenia is one case where the "Big Bang" worked, but it was a fortunate convergence of circumstances that made it possible: imminent EU accession, both minister and budget director as champions, and resident advisor support from IMF. As a result, after just one year of pilot work, the minister decided to establish a program structure for the whole government and reflect them in the budget documents, thereby avoiding any problems with how to handle the interim period. The downside, however, is that some aspects of the new approach have yet to become fully entrenched in line ministries, especially those that saw this initiative as a top-down exercise. The circumstances that permit a "Big Bang" approach are not often replicated, however, especially in LICs. 

TNM/09/01

International Monetary Fund

Fiscal Affairs Department

700 19th Street NW

Washington, DC 20431

USA

Tel: 1-202-623-8554

Fax: 1-202-623-6073 